\title{
La escucha (en la) crónica de Juan Villoro
}

\section{Listening (in the) Chronicle of Juan Villoro}

\section{Resumen}

Juan Villoro, consagrado en la Literatura Latinoamericana como narrador de ficción y autor destacado en el mercado editorial de Literatura Infantil, ha desarrollado de manera paralela una notable producción cronística que ha recibido escasa atención crítica. La lectura de estas últimas en conjunto con entrevistas dadas por el autor permitió advertir una autorrepresentación como cronista versado en el arte de escuchar. Tema que constituye la excusa para revisar parte de su producción con el foco en su oído atento a las expresiones y manifestaciones de la cultura masiva. Interesa aproximarnos a la escucha crónica, aspecto característico de su estética, a partir de analizar el lugar prioritario de la voz del locutor futbolístico Ángel Fernández, los vínculos con la contracultura mexicana y la construcción de un mito de origen que abreva de la cultura de masas.

Palabras claves

Literatura latinoamericana, Juan Villoro, crónica, escucha.

\begin{abstract}
Juan Villoro, consecrated in Latin American Literature as a fiction narrator and prominent author in the Children's Literature publishing market, has developed in parallel a remarkable chronological production that has received little critical attention. The reading of these chronicles in conjunction with interviews given by the author allowed us to notice a selfrepresentation as a chronicler versed in the art of listening. Theme that is the excuse to review part of his production with the focus on his ear attentive to the expressions and manifestations of mass culture. It is interesting to approach chronic listening, a characteristic aspect of its aesthetics, from analyzing the priority place of the voice of the soccer announcer Ángel Fernández, the links with the Mexican counterculture and the construction of a myth of origin that draws on mass culture.
\end{abstract}




\section{Introducción. El cronista ante la cultura del entretenimiento}

\begin{abstract}
"Nosotros, espectadores y lectores, ya no venimos de la selva o de la sabana, ya no nos impacta fatalmente el shock of recognition de la jungla de asfalto, ya no provenimos dogmáticamente de las tradiciones recién quebrantadas por el capitalismo. Venimos de las películas[...]. Monsiváis, Carlos. Aires de familia.
\end{abstract}

"Ya es un hecho que las masas en América Latina se incorporan a la modernidad no de la mano del libro, no siguiendo el proyecto ilustrado, sino desde los formatos y los géneros de las industrias culturales de la radio, del cine y de la televisión". MartínBarbero, Jesús. Medios de comunicación

Juan Villoro (Ciudad de México, 1956) como heredero de la llamada narrativa de la Onda se desentendió de la búsqueda de la identidad nacional y priorizó el sentido del oído al de la vista para acercarse a la cultura masiva. La Onda, advierte la crítica Margo Glantz, "se maneja como un elemento sonoro y la utilización del término que se aplica a un tipo de literatura hecha por jóvenes que están en la onda musical específica, la del rock, nos lleva a una construcción en la que lo improvisado está dentro del orden de la variación temática que surge [...] dentro del jazz o del rock" (246). Es posible advertir en la escritura de Juan Villoro ecos de esa atracción por lo auditivo que, en sus autorretratos, se manifiesta a través de la imagen de cronista versado en el arte de escuchar. En dicha autofiguración entran en juego particularidades como su escolarización en una lengua extrajera que lo sensibiliza con el lenguaje y también la priorización de un abordaje temático desde el propio deseo, temas que serían objeto de otro artículo. En esta instancia, pretendemos aproximarnos a la escenificación de esa escucha que, como 
mencionamos, se muestra motivada por la cultura masiva indefectiblemente popular.

En consonancia con la revisión crítica que los estudios culturales mexicanos de las décadas previas habían realizado interpretando sin preconceptos la relación de los medios masivos con la cultura (Martín-Barbero 1987; Monsiváis 1987, 1989; García Canclini 1989), Villoro sostiene: "para conocer una época tenemos que saber cómo se entretiene la gente en esa época y nada define mejor a nuestra época en términos de espectáculo que la pasión por el fútbol". ${ }^{1}$ Esta inclinación por comprender los modos que asume la diversión obliga a recuperar en especial a Carlos Monsiváis, escritor que dedicó buena parte de sus crónicas a registrar una Ciudad de México que se había vuelto espectacular. Tempranamente, en 1973, este cronista había desafiado a sus contemporáneos a detenerse en espacios y personajes marginales para el campo artístico:

en el vacío social y político creado a partir del dramático 1968, todo adquiere otra dimensión y, a la vez, no alcanza sitio preciso. De modo confuso, se intuye que todo es política aunque la interpretación y la ubicación correctas todavía resulten muy difíciles. Por lo pronto, acumulación de material: ¿quién no quiere oír los tumultuosos y tempestuosos relatos de lo que hizo Irma Serrano, de lo que hace Irma Serrano, de su ostentación y su instinto financiero, de sus arranques y la cuidadosa divulgación de sus arranques? (Monsiváis, Entre apariciones 56)

La apuesta de Carlos Monsiváis resultó osada por asumir sin prejuicios temas provenientes del corazón de la cultura de masas como lo era, en el caso referido, el show de la vedette Irma Serrano. Es decir, posar la mirada en el aspecto más farandulesco del espectáculo. Este "voyeur urbano" (Salazar) empezó a

${ }^{1}$ Frase extraída de la presentación audiovisual realizada por el escritor para publicitar Balón dividido. El video se encuentra disponible en: https://www.youtube.com/watch? $\mathrm{v}=56 \mathrm{Sd} 4 \mathrm{CgPYb} 0$ 
ocuparse desde aquel entonces de aquellas manifestaciones que llamaban la atención de públicos multitudinarios por considerar que eran materiales de gran riqueza para reflexionar sobre su contemporaneidad. Gracias a su lúcida mirada, legitimó el tratamiento literario de zonas desacreditadas de la cultura como, por ejemplo, el teatro de revistas y la canción pop (Viú Adagio). Inscribimos a Juan Villoro en dicha tradición por las temáticas elegidas (el fútbol constituye una de sus predilectas) y sobre todo porque su abordaje de esta cultura del entretenimiento también da cuenta de una conciencia aguda sobre el impacto que el desarrollo de lo que podríamos englobar bajo la categoría industria cultural tuvo sobre la vida cotidiana. El escritor atribuye su sensibilidad hacia la diversidad cultural al hecho de haber vivido el impacto que supuso la aparición del México de masas:

La idea de un México de sombrero de charro, de canción ranchera, bravío y que tenía que ver con gestas de caballería de Pancho Villa, todo eso a mí me resultaba bastante extraño. Y por otra parte, el mundo estaba cambiando en direcciones distintas. Las grandes ciudades comenzaban a crear una tensión y una cultura propia, empezaba la cultura de masas a tener una impronta muy fuerte. Entonces, ¿cómo reconcilias la historia de un país que te está hablando de un esplendor fundamentalmente agrícola, de una identidad nacional que se expresa de una manera rústica y monolítica, y que viene del México revolucionario, con un país en donde tú ves a "Don Gato y su pandilla", el "Superagente 86", lees los cómics, llega la música de los Beatles, la minifalda, y todo eso? (Villoro 2012)²

Juan Villoro percibió un cambio de escenario: de aquella ciudad con una fuerte impronta nacionalista de comienzos del siglo XX más próxima a una visión estática y provinciana a una sociedad cambiante y fundamentalmente heterogénea que lo fascinó por la riqueza de los productos culturales. Ante esa transformación,

\footnotetext{
${ }^{2}$ Fragmento de la entrevista que Simón Henao y Carlos Walker (2012) le realizan a Juan Villoro para la revista Zama.
} 
los clásicos símbolos de la mexicanidad empezaban a tornarse caducos. De ahí, la necesidad de una renovación de temas y figuras que permitieran abordar una realidad producto de la convivencia de tradiciones e imaginarios de diversas procedencias. La toma de conciencia (y la consecuente distancia) respecto a la representación de un México uniforme y monolítico le permitió a Juan Villoro advertir lo que Jesús Martín-Barbero ha nombrado como una "acelerada desterritorialización de las demarcaciones culturales" (Medios 169).

Atentos al deseo del escritor de representar su época a través de esa pasión de multitudes que lo afecta y al mismo tiempo lo fascina en términos personales, proponemos reflexionar sobre la incidencia que dicho posicionamiento presenta en su imagen de cronista. La hipótesis de lectura que guía el análisis es que el autor construye una escucha crónica que aparece como núcleo de su interés y se muestra a nivel autofigural escenificando una deuda con la cultura masiva. El escritor ha señalado en más de una oportunidad que su inclinación por la literatura responde en gran medida a su fascinación por la popularmente denominada "voz del Azteca", el locutor de fútbol más famoso de México Ángel Fernández. En efecto, interesa indagar la elección de esa figura así como la posibilidad de inventar a través de ella un mito de origen no literario para su escritura. Pretendemos mostrar que la autofiguración como cronista atento a los modos de contar cobra importancia en el marco de una poética que pone el foco en la representación de las voces de los otros.

\section{Incursiones en la contracultura}

"Las luchas generacionales acerca de lo necesario y lo deseable muestran otro modo de establecer las identidades y construir lo que nos distingue. Nos vamos alejando de la época en que las identidades se definían por esencias ahistóricas: ahora se configuran más bien en el consumo, dependen de lo que uno posee o es capaz de llegar a apropiarse". Néstor García Canclini, Consumidores y ciudadanos. 
Juan Villoro deja ver sus gustos y preferencias personales a partir de la identificación con valores que han caracterizado al movimiento de la contracultura mexicana cuyo auge en algunas de sus manifestaciones tuvo lugar en la segunda mitad de los años sesenta con la publicación de La tumba (1964) y De perfil (1966) de José Agustín y Gazapo (1965) de Gustavo Sáinz. La burla hacia actitudes formales y solemnes así como el ansia de libertad y autenticidad se advierten en Villoro, en parte, también por la distancia que establece con la generación de su padre Luis Villoro, reconocido filósofo y docente universitario. Un pasaje autobiográfico del año 2012 resulta interesante para aproximarnos a esta cuestión:

Mi padre siempre ha dormido en piyama. Lo recuerdo en las noches de mi infancia con una prenda azul clara, de ribetes azul oscuros, y así lo veo cuando lo visito a sus ochenta y siete años en sus ocasionales cuartos de enfermo.

En la adolescencia adquirí una costumbre que no pasó por la reflexión ni por sólidas argumentaciones, pero que -como todo en aquel tiempo- tuvo un peso simbólico: dormir sin piyama. Para alguien formado en la era del rock y la sicodelia, que soñaba con el lado oscuro de la luna, la ropa de noche significaba un resabio demasiado infantil o demasiado formal. (Villoro, 8, 813 )

José Agustín, a quien el escritor le dedica Tiempo transcurrido (1986), sostiene en el clásico libro La contracultura en México que se trató de "una serie de movimientos y expresiones culturales, usualmente juveniles, colectivos, que rebasan, rechazan, se marginan, se enfrentan o trascienden la cultura institucional[...]" (129). Este imaginario en esencia disruptivo se expresa en la cita de Juan Villoro en principio en dos cuestiones: la elección del rock, género musical que encierra un guiño a los escritores de la narrativa de la Onda entre los que se destacan los ya mencionados José Agustín y Gustavo Sáinz; y la actitud de rebeldía traducida en la elección de no usar "uniforme para soñar" (13) como simbolización 
del enfrentamiento al mundo académico. El escritor estudió la carrera universitaria de sociología, obtuvo un puesto como agregado cultural en la embajada de México en Berlín (1981-1984), becas en el Instituto Nacional de Bellas Artes (1976-1977) y en el Instituto Goethe en Munich y numerosos premios (1988, 1993, 1999, 2001, 2004, 2006, 2008, 2015 y 2019). Sabemos que paralelamente a este trayecto de consagración académica y literaria, incursionó en territorios culturales próximos a ámbitos más populares con los que construyó su imagen de cronista. Fue letrista de la banda Los Renol, guionista y conductor del programa radial "El lado oscuro de la luna" (1977-1981), columnista del Mundial de Francia en La Jornada (1998), comentarista televisivo del Mundial de Alemania (2006) y coconductor del programa Ludens sobre el Mundial de Sudáfrica (2010). ${ }^{3}$ Sin desconocer estas facetas notablemente diferenciadas que presenta el escritor y partiendo de que resulta imposible separarlas, interesa recuperar sus intervenciones en los medios para dar cuenta de su filiación a espacios y manifestaciones masivas.

El crítico español Juan Antonio Malosiver Ródenas señala dos cuestiones como indicios de la sensibilidad del escritor hacia la contracultura: las escasas referencias al Arte con mayúsculas que hay en sus obras y la identificación del autor con el periodismo. Respecto a este último, "en Palmeras de la brisa rápida [1989] el propio Villoro, al llegar a la posada de Toledo de Mérida, nos dice: 'anoté la profesión que usurpo desde hace años para llenar cuestionarios: 'periodista'. 'Escritor huele a pipa apagada, apotegma de dispéptico, edición intonsa, dedo ensalivado, pantuflas rancias" (Malosiver Ródenas 38). En oposición a la imagen de escritor, figura solemne revestida de notable autoridad, Juan Villoro se definió (paradoja mediante porque ya era un escritor reconocido) como periodista optando

${ }^{3}$ El testimonio del crítico italiano Alejandro Rossi resulta elocuente del desapego de Juan Villoro por los ámbitos institucionales: "Admiro la habilidad, mezcla de cortesía y tozudez, con que Juan Villoro ha esquivado las tentaciones usuales en la carrera de un escritor mexicano. Estuvo observador fugaz- en la diplomacia (con él crucé en Check-Point Charlie) y ha huido de las varias burocracias y sus servidumbres jerárquicas. Soy testigo de sus bostezos disimulados cuando por un breve período trabajamos juntos en una oficina sin ventanas. Ha dado vueltas por la Academia, pero no se ha estacionado en ningún cubículo" (La casa 84).

${ }^{4}$ Para una revisión biográfica del autor, véase: "Villoro, Juan", Diccionario de escritores mexicanos Siglo XX: desde las generaciones del Ateneo y novelistas de la Revolución hasta nuestros días. tomo IX (U-Z). México: Universidad Autónoma de México, 2007. 
así por una profesión que en términos simbólicos resulta más vulgar, entre otras cuestiones, por la dependencia económica respecto del medio para el que se trabaja. En consonancia con su capacidad de elegir sin estar condicionado por parámetros de prestigio cultural, debemos señalar ya que en sus crónicas cobra relevancia, el hecho de asumir su condición de hincha de fútbol. Ello autoriza al cronista a intervenir no sólo desde la prensa escrita sino también desde la radio y la televisión convirtiéndolo en una figura destacada de la esfera pública nacional. "La afición en primera persona" (Dios es redondo) constituye un texto paradigmático para reflexionar sobre la construcción de dicha imagen:

Durante nueve años contados segundo a segundo, miré por la ventana del salón el patio donde los suéteres marcaban las porterías. Ese rectángulo era la libertad y era mi idioma. Si algo aprendí en la ardua pedagogía del Colegio Alemán es que nada me gusta tanto como el español. Como las pasiones son caprichosas, asocié para siempre el gusto por gritar en la lengua proscripta con la pelota que daba el sentido al recreo. (19)

El fútbol se constituyó en la pasión que le permitió encontrar un sentido de pertenencia que no hallaba en esa lengua extranjera, esa escolarización rígida y esa cultura puritana del Colegio Alemán. Por ello, se hizo hincha del Necaxa, el club de su barrio, que resultó una "elección caprichosa porque no era un equipo fuerte, que garantizara títulos y prometiera domingos fáciles" (Villoro, Dios 19). Así, la cancha se convirtió en un territorio de libertad que simbolizó la expresión genuina, la cultura del grito, lo más lindo de la infancia. Interesa destacar que la aproximación a dicha temática el escritor la construye con una mirada direccionada por su deseo sin perder de vista el abordaje sociológico. En relación con ello, resulta interesante traer a colación la concepción que tiene de sus lectores. En Tiempo transcurrido, aclara: "un libro para fanáticos del rock y un libro para sordos. Hay suficientes guiños para quienes han hecho de esta música un artículo de fe, pero las 
crónicas de este libro rebasan la inmediatez del fenómeno roncanrolero". 5 De modo similar, en Dios es redondo expresa: "He querido escribir para los seguidores del fútbol, pero también para sus críticos, para quienes no se interesan en los goles pero buscan comprender el delirio[...]" (13). Juan Villoro concibe dos tipos de lectores: unos que se acercarían a sus textos motivados de manera exclusiva por la temática elegida y otros sin interés particular que podrían sentirse atraídos por la lectura crítica de fenómenos contemporáneos. Si apelamos al concepto "ciudad letrada" de Ángel Rama que definiría un adentro y un afuera, lo que pertenece a ella y lo que no, podríamos tal vez visualizar con mayor claridad que el autorretrato de cronista, construido a partir de su predilección por temas que atañen a las mayorías, traspasa de manera notable la ciudad institucionalizada.

\section{Un excéntrico mito de origen}

La filiación del cronista al universo simbólico de la contracultura al que hemos referido se registra en la operación autoral que interesa iluminar para aproximarnos a su propia ficción de autor de gustos pop. En entrevistas dadas por el escritor, se insiste en la siguiente idea: su atracción por la literatura no se debió a la lectura de libros ni al valor dado a las bibliotecas sino a las trasmisiones de radio.

La radio me ayudó a concebir las palabras como algo que no es utilitario, es decir, las palabras como símbolos mágicos. Las palabras como forma de la realidad, a entender que un relato mejora la realidad si está bien contado. Es el principal atributo de la literatura, hasta ese momento yo no sabía que eso podía ser literario, pero me parece que la literatura acrecienta la experiencia del mundo. (Villoro) ${ }^{6}$

${ }^{5}$ Palabras de la contratapa de la edición que Fondo de Cultura Económica realiza en 2006 en la colección popular.

${ }^{6}$ Fragmento extractado de la entrevista radial que Carlos Escutia le realizó a Juan Villoro en 2016. Disponible en https://criterionoticias.wordpress.com/2016/10/21/juan-villoro-literatura-radio-yperiodismo/ 
No fue literatura difundida por dicho medio lo que lo sedujo sino los partidos de fútbol narrados por Ángel Fernández, periodista que según Villoro se constituyó en una leyenda del deporte mexicano por sus apasionados e ingeniosos relatos. Aquellas transmisiones dejaron una marca indeleble en la memoria de este escritor porque dicho locutor se detenía en la elección del vocabulario así como en la expresión deseada para desnaturalizar las imágenes clisé. Queremos decir que no usaba el lenguaje de la comunicación regido por la economía de las palabras en pos de la eficacia del mensaje sino un lenguaje polisémico que cautivaba por su originalidad: “el gran héroe de mi infancia fue el locutor Ángel Fernández. El fútbol me cautivaba porque él le había agregado la decisiva pista sonora de la épica. $\mathrm{Su}$ inspirada espontaneidad era siempre una perfecta versión definitiva" (Villoro, Dios 129). La singularidad de su voz así como su imaginación, ingenio y creatividad para relatar los partidos, su capacidad de inventar apodos y sus frases célebres hicieron de él una estrella nacional. Interesa aquel recuerdo porque muestra de manera clara que la voz de Ángel Fernández le permitió a Villoro reconfigurar la noción de lo literario. En Dios es redondo, el autor cuenta que cuando el locutor pasó de la radio a la televisión la cancha se convirtió en una excusa para la metáfora. Se refiere a la libertad que experimentó Ángel Fernández con la aparición de la televisación del fútbol ya que, si el público estaba viendo el partido (lo que pasaba en la cancha), él como relator podía desentenderse del registro descriptivo al que lo obligaba la radio. La aparición de la televisión entonces no significó la extinción de los locutores sino que, por el contrario, librados de tener que contar lo que estaba pasando (quién tiene la pelota, hacia dónde corre, a quién le da el pase) pudieron dedicarse a comentar el partido dando rienda suelta a la imaginación. Juan Villoro recuerda en particular el modo en que Ángel Fernández contó, por ejemplo, la incorporación del jugador Cristóbal Ortega al club América: “Cuando Cristóbal Ortega debutó con el América dijo en forma inolvidable: 'Señoras y señores, hemos vivido en el error: ¡América descubrió a Cristóbal!” (Dios 218). Esa reinvención del oficio de locutor en tiempos del reinado televisivo, sugerida por Villoro, se cifró 
en reafirmar lo sustantivo del narrador: la capacidad de despertar el deseo de escuchar una historia. Esa es la lección principal que el escritor hereda.

La retórica de Ángel Fernández cargada de excesos y delirios vive en la memoria del pueblo mexicano: "la obra de Ángel está en quienes recordamos sus fogonazos, pero también en quienes repiten sus hallazgos sin saber que son de él" (Villoro, Dios 221). Esta "voz del Azteca", representante de la cultura popular, comenzó relatando fútbol en la radio aunque paradójicamente encontró su sello personal como comentarista de partidos televisados. Se abocó a generar tensiones narrativas, adjetivar las jugadas, bautizar ingeniosamente a jugadores y equipos, en definitiva, a generar nuevos sentidos. Juan Villoro, después de haberse encontrado cara a cara con Ángel (intercambio que como lectores podemos prefigurar como un momento anhelado), escribió la crónica “Conversación con Ángel Fernández” en la que precisó las principales estrategias utilizadas por el locutor: el hecho de hacer que los datos al alcance de todos estén al servicio del relato convirtiéndose en un insumo que el cronista debe saber mezclar; la utilización del apodo como un emblema en un escudo otorgando identidad; y el uso de metáforas épicas en reemplazo de las expresiones técnicas. La gran lección de este maestro de la palabra masiva que renovó el imaginario del fútbol fue entonces el del valor de la polisemia: "sus narraciones de fútbol me revelaron que todo podía decirse de otro modo" (Villoro, Los once 4). El deseo por lo literario de Juan Villoro, en definitiva, estuvo estimulado por ese universo de infinitas posibilidades expresivas que le abría ese "lenguaje de fábula" (4).

Permita el lector la siguiente digresión para vincular estas reflexiones con la concepción que Juan Villoro presenta del género crónica. La caracterización del cronista como un "periodista fabulador" se vuelve doblemente pertinente ya que, al tiempo que resulta representativa del modelo elegido (Ángel Fernández es un fabulador nato), permite pensar su propia práctica discursiva. La lectura de los prólogos a sus antologías, desde Tiempo transcurrido. Crónicas imaginarias hasta ¿Hay vida en la tierra?, permite observar que el escritor transita constantemente la lábil frontera que puede establecerse entre las historias reales y las historias 
imaginadas dispuesto a buscar insumos en la imaginación antes que en los testimonios. El quid de esta narrativa anfibia se cifra en el arte de contar en desmedro de la temática elegida y, por ello, su posicionamiento estético encuentra una clave en la "mirada del fabulador" (Safari 9) desde la que leyó el mundo con la intención de mezclar realidades. ${ }^{7}$ La tensión entre un registro imaginario y uno realista se vuelve una dualidad constitutiva de la prosa del cronista mexicano, que por momentos se viste de fabulador (escritor de ficción) y por otros de reportero (periodista especializado en crónicas). El estilo de Juan Villoro se consolida en esa fusión irresoluble entre la invención y lo real registrando la experiencia de un sujeto que "reparte su escritura entre la verdad y la fantasía" (Villoro, Safari 9). En resumidas cuentas, a un siglo de la emergencia del género, este autor ostenta su hibridez al afirmar que ejerce de manera intermitente el oficio de periodista así como el de narrador ficcional y traduce la urgencia del género en términos futboleros: el apuro por entregar la nota no está marcado por el día siguiente sino por el comienzo del siguiente partido. ${ }^{8}$

En un gesto típico de escritor moderno que crea su propia tradición, Juan Villoro ubica en el origen de su vocación literaria al locutor estrella Ángel Fernández y, de esta manera, forja un excéntrico mito de origen literario como cronista, vinculado a las pasiones de su infancia y, en particular, a la cultura radiofónica. La elección de dicho antecedente visibiliza una singularidad que podría explicarse en términos generacionales: Carlos Monsiváis, perteneciente a la generación anterior, construyó su mito de origen identificándose con el consumo literario de versiones ilustradas de la literatura universal vendidas en los quioscos. De la expresión "consumo literario" hacemos énfasis en el primer término para subrayar que no hubo en aquella autofiguración un valor en torno al objeto libro

${ }^{7}$ Pareciera haber un trasfondo real al que Villoro aspira al escribir crónicas sin ninguna imposición del registro testimonial. En ¿Hay vida en la tierra?, advierte: "No he querido construir cuentos sino buscarlos en la vida que pasa como un rumor de fondo, un sobrante de la experiencia que no siempre se advierte" (9).

${ }^{8}$ Este cronista mundialista que desde 1990, cada cuatro años, tiene una cita con el Mundial de Fútbol ha expresado: "escribí [sobre el mundial de Sudáfrica 2010] en el estado de trance al que te someten Internet, la obligación de entregar y la angustia de que ya comienza otro partido" (Villoro, Ida y vuelta 17). 
sino en todo caso una identificación con un acercamiento a la lectura de tipo más popular. En sintonía con este distanciamiento de la lectura como práctica culta aunque profundizando aún más el gesto de ruptura, Juan Villoro detecta que fueron aquellas transmisiones masivas de fútbol las que despertaron su deseo literario. En la entrevista "Juan Villoro: "no creo que haya literaturas individuales"” (Tentoni), el escritor señala que no se trata de que en su casa no haya habido bibliotecas sino que estas no captaron su atención:

Tu madre por su parte es psicóloga, ¿no? ¿Cómo era la biblioteca de tu casa?

Sí, mi madre es psicóloga hasta la fecha. La biblioteca no era un estímulo. Dice Borges que el principal descubrimiento de su vida fue la biblioteca de su padre, o sea que ese fue el descubrimiento del universo, para él. En mi caso no fue así, porque yo me sentí rechazado por la biblioteca, eran libros aburridos para un niño. Y yo no fui un niño libresco, para nada. Me gustaba mucho la palabra pero en las voces de los narradores del fútbol de la radio, los rapsodas del momento. ( $\mathrm{s} / \mathrm{n})$

Se advierte en esta respuesta el rechazo a la biblioteca como símbolo del conocimiento que una vez más interpretamos como un posicionamiento de enfrentamiento al mundo adulto y académico. Interesa señalar en particular un doble movimiento: la distancia establecida discursivamente hacia la imagen del escritor como sujeto lector (cuya figura paradigmática encuentra en Borges) sobre la que se fundaron las autorías desde el siglo XIX hasta mediados del XX y, en ese mismo movimiento, la confesión de su predilección por la palabra escuchada. La afinidad que podríamos marcar entre Monsiváis y Villoro radicaría entonces en la simpatía por aspectos culturales marginales que simbolizan rupturas notables con los valores hegemónicos de cada época. En el marco de una cultura nacional que aún operaba en los años cincuenta cuando se formó Monsiváis que sostenía el valor de la cultura letrada cifrada casi de manera exclusiva en el libro, la reivindicación 
de lecturas de divulgación (versiones adaptadas en distintos sentidos) significó un enfrentamiento a los ámbitos legitimados del saber. De manera análoga, advertimos en el caso de Villoro que habiendo perdido interés la oposición lector/consumidor porque en las sociedades contemporáneas todos se saben sujetos consumidores, este autor formado en la contracultura no podía sino encontrar un estímulo para escribir en un espectáculo masivo y popular como el fútbol. No dejamos de señalar además que dicho deporte presenta una cuestión de género ya que Villoro al ratificarse como un cronista literario de fútbol apela a una temática tradicionalmente asociada al ámbito masculino. Aunque sus crónicas no reproducen ni se enuncian desde la concepción de un sujeto estereotipadamente masculino como se podría asociar a la figura del fanático. Según el relato propuesto por el escritor, él se representa ante todo como un aficionado que se convierte en escritor. ${ }^{9}$ Pensamos el término aficionado como un sujeto moderado que no se caracteriza por la irracionalidad del fanático. De hecho, este cronista no pierde el sentido del humor que lo caracteriza para hablar de otros clubes ni tampoco parar referir a su propio equipo. Este hincha moderado que es capaz de reírse de sus propias derrotas resultaría representativo de la idiosincrasia mexicana.

\section{La voz en la escritura de Juan Villoro}

"Cambios que nos enfrentan a una acelerada desterritorialización de las demarcaciones culturales y a desconcertantes hibridaciones en las identidades. La cultura cotidiana de las mayorías, no sólo en las ciudades sino también en el campo, se halla cada día más moldeada por las propuestas, los modelos y las ofertas culturales de los medios masivos". Jesús Martín-Barbero, "Medios de comunicación".

${ }^{9}$ Juan Villoro construye su presencia pública en torno al fenómeno del fútbol no sólo escribiendo sobre dicha temática sino también comentando partidos en televisión o dictando conferencias. Referimos a su rol como comentarista del Mundial de Alemania (2006) para la televisión mexicana, la conducción junto con Mauricio Mejía de la temporada del programa televisivo Ludens dedicado al Mundial Sudáfrica 2010 emitido por Canal 22 de Conaculta y la participación en el ciclo "Cómo leer..." de la Biblioteca Vasconcelos con una exposición titulada "Cómo leer un partido de fútbol". 
Inscribimos las crónicas de Juan Villoro en la tradición literaria latinoamericana de representación de las voces de los otros entre las que se destacan las personalidades mundanas del porfiriato de Manuel Gutiérrez Nájera, las entrevistas a escritores de Enrique Gómez Carrillo y a hombres famosos de Juan José de Soiza Reilly, la recreación del habla popular en las aguafuertes de Roberto Arlt, la voz del testimonio de Elena Poniatowska, la palabra del "intelectual público" (Sánchez Prado) de Carlos Monsiváis, el argot caribeño de Edgardo Rodríguez Juliá y las “vidas de vivos” de María Moreno, entre otras. El interés por metarreflexiones que abordan la representación de la voz nos lleva a hacer foco en la confrontación de la escritura de la argentina María Moreno y la de Juan Villoro para iluminar variaciones que le otorgan un rol central al acto de escucha. Ambos escritores coinciden en advertir que su vínculo con la literatura provino de la radiofonía antes que del hábito de la lectura. ${ }^{10}$ Sin embargo, interesa detenernos en la tematización de aspectos propios del fenómeno de la voz, escenificación que, en ambos casos, devuelve imágenes de cronistas receptivos ante las diferencias que emergen de voces que gritan, susurran, imploran, declaman, confiesan, lloran, amenazan, ordenan o demandan.

En el caso de las crónicas de María Moreno, se pone de manifiesto una aguda percepción de los registros de las voces como puede leerse en sus colaboraciones para el semanario argentino Siete días. En "Beatriz Guido: la pianista que no dio en la tecla", señala: "Habla -valga la ironía- como en las vísperas de un incendio. Es decir, que carece de esa reserva pacata de los famosos, conscientes de que sus metidas de pata o sus exabruptos de sangre en el ojo, tal vez, no se los lleve el viento" (47). Respecto a Claudia Sánchez, encuentra que la voz de la ex modelo argentina es "en idéntica medida pueril, aristocrática y cachadora"

\footnotetext{
${ }^{10}$ En la crónica "Leer hasta que la muerte nos separe", María Moreno plantea que primero tuvo lugar una formación auditiva y luego, una escrita: "En el principio la literatura me llega resumida, adaptada y traducida a través de las voces del radioteatro. Escucho Cumbres borrascosas, Los miserables, Facundo, fascinada por tonos de recitación y énfasis modulados. Ya entonces o desde entonces no me gustan las tramas. Cuando encuentro, muy temprano, las obras de Colette, me hipnotiza la escritura de una voz" (Subrayados 109).
} 
(38) y que el boxeador Sergio Víctor Palma habla con una "voz neutra" (39) y un "lenguaje maniáticamente sensato con el que oculta la timidez y el miedo al papelón" (39). ${ }^{11}$ Este tipo de apreciaciones recurrentes en su escritura exhiben a una cronista atenta a la dicción y las particularidades de la voz (su melodía, su cadencia, su modulación) en tanto elementos constituyentes del significado, un plus de sentido asociado a la palabra que esta escritora experta en el arte de la entrevista se detiene a registrar.

A diferencia de la escucha de María Moreno que repara en la riqueza de las modulaciones vocales, el cronista mexicano se muestra seducido por los modos de contar y centra su atención en la elección de las palabras. Su estética se basa en la sagaz percepción de lo que se dice o se deja de decir, la manera en que se expresa o se calla, el modo en que se comunican los pensamientos (hemos referido en el apartado anterior a la seducción que le despiertan los relatos de Ángel Fernández). Esta particular sensibilidad del escritor aparece tematizada en Palmeras de la brisa rápida cuando Villoro recuerda las historias de su abuela:

Todos los días renovaba su decencia describiendo con lujo de detalle la indecencia de los demás. Si hubiera dicho 'Fulana se fue con Mengano' jamás habría reparado en ello, pero cuando se refería a ‘jesa que se revuelca con los turcos!', me daban ganas de conocerla. La frase tenía una innegable carga sexual y hacía pensar en amores circenses, arábigos, magníficos. (14)

De "Fulana se fue con Mengano" a "¡esa que se revuelca con los turcos!" es posible visualizar un pasaje que puede sintetizarse como del dato al relato ya que la primera frase se limita a brindar información precisa y objetiva (si se nos permite este adjetivo) mientras que la segunda, por el contrario, presenta una carga subjetiva notable percibida en el subjetivema "revuelca". Villoro disfruta de los universos de

\footnotetext{
${ }^{11}$ A excepción de la crónica sobre Sergio Víctor Palma, recopilada en Vida de vivos, el resto se encuentran actualmente dispersas ya que no han sido antologadas en libros.
} 
sentido que cada palabra habilita y, por eso, no le da lo mismo una u otra. Nuevamente el escritor repara en una persona de notable inventiva, experta en el arte de generar misterios con palabras, que apela a un enorme bagaje de referencias culturales para seleccionar y combinar imaginarios, tradiciones y símbolos. Esa escucha se traduce en su escritura -queremos señalarlo aunque no sea posible profundizar en ello en este artículo- en el magistral manejo de la definición que exhibe en las crónicas dedicadas a esa pasión de multitudes que es el fútbol. Cabe señalar que no se trata de clásicas definiciones de diccionario $\mathrm{y}$, menos aún, académicas u objetivas. En la crónica "Infancia en la tierra", el escritor advierte: “Definir al balompié como 'deporte' equivale a definir a la perdiz en pipián como 'alimento"' (Los once 142). Villoro como todo cronista de fútbol habla de lo que los lectores ya conocen, entre otras cuestiones, porque habla en diferido, esto es, narra después de los acontecimientos. En este sentido, particulariza una dificultad que deben afrontar este tipo de narraciones: "ningún libro descubrirá quién es Pelé o el Chicharito Hernández. Eso ya está en la mente del aficionado. El raro misterio de las palabras consiste en darle valor y emoción a lo que ya sabíamos" (Villoro, Balón 19). Sea a partir de definiciones o de otros recursos, Villoro despliega su maestría en la invención de tramas producto de un oído entrenado en las variaciones léxicas.

\section{A modo de conclusión}

La cultura masiva constituyó a los ojos de Juan Villoro una fuente inagotable de recursos y experiencias. Lo atrapó, lo fascinó, lo incitó, lo interpeló, en definitiva, lo motivó a indagar pliegues y matices del sugerente universo de lo real. Esta inclinación temática nos obligó a inscribir al autor en la tradición de Carlos Monsiváis por el valor que ambos le otorgaron al entretenimiento así como a sus figuras más representativas. Sus búsquedas estuvieron basadas en la convicción de que conocer los gustos de las mayorías permitiría narrar su propia época. Mientras Monsiváis se concentró en referentes de la música pop y del teatro de revistas, Villoro, se ocupó del rock y del fútbol. Desarrollamos además la 
atracción del escritor por valores y símbolos del movimiento literario de la contracultura mexicana visibilizando así un doble movimiento: el desapego de Juan Villoro a los ámbitos institucionalizados y su simpatía por espacios, medios y expresiones culturalmente más informales cuyos valores de legitimación parecían ajenos al campo artístico.

A tal punto el escritor se interesó por dicha temática que la autorrepresentación construida en sus crónicas (y reforzada en entrevistas) muestra una imagen de cronista versado en el arte de escuchar. Iluminamos que en el origen de ese saber oír se encuentra Ángel Fernández y su magistral manejo de la palabra en pos de hacer visible la invención de un excéntrico mito de origen. Juan Villoro forjó una identidad literaria sustentada en saber oír, un saber indispensable para poder contar historias, y en seguir su pasión ya que los temas abordados no fueron impuestos por el medio o la agenda mediática sino por su propio interés. A modo de síntesis, recuperamos la expresión escucha crónica, que guía la lectura del artículo, para especificar dos sentidos que anidan en ella: por un lado, referimos a la escucha en la crónica y, por otro, a una escucha crónica. Crónica refiere entonces al género discursivo en tanto espacio escritural en el que la ficción auditiva cobra relevancia. Y, a la vez, en tanto referencia temporal, habilita otro sentido: la escucha al tornarse crónica se convierte en un rasgo estilístico de un autor que entrenó su oído en las variedades de la lengua, experiencia enriquecida sin lugar a dudas por la temprana exposición al idioma del Sturm und Drang y afinada por el oficio de traductor que ha ejercido paralelamente. 


\section{Bibliografía}

Díaz Quiñones, Arcadio. Sobre los principios. Los intelectuales caribeños y la tradición. Buenos Aires: Universidad Nacional de Quilmes, 2006.

Diccionario de escritores mexicanos Siglo XX: desde las generaciones del Ateneo y novelistas de la Revolución hasta nuestros días. tomo IX (U-Z).

Aurora Ocampo (dir.), México: Universidad Autónoma de México, 2007.

Escutia, Carlos. "Juan Villoro; Literatura, radio y periodismo", Programa radial de la Universidad Autónoma del Estado de México (UAEM), 2016. https://criterionoticias.wordpress.com/2016/10/21/juan-villoro-literaturaradio-y-periodismo/

García Canclini, Néstor. Culturas híbridas: estrategias para entrar y salir de la modernidad. México: Grijalbo, 1989.

Glantz, Margo. “La onda diez años después: ¿epitafio o revalorización?”, Esguince de cintura. Ensayos sobre narrativa mexicana del siglo $X X$. México: Lecturas mexicanas, 1994. 244-264.

Grotto, Livia. "Juan Villoro: un itinerario en la traducción”, en Estudios de teoría literaria 7, 13 (2018). 111-123.

Henao, Simón y Carlos Walker. "La literatura es un arte visual. Entrevista a Juan Villoro”, en Zama 4 (2012). 197-201.

José Agustín. La contracultura en México: la historia y el significado de los rebeldes sin causa, los jipitecas, los punks y las bandas. México: Grijalbo, 1996.

Martín-Barbero, Jesús. “Medios de comunicación”, Diccionario de Estudios Culturales latinoamericanos, Mónica Szurmuk y Roberto Mckee Irwin (coord.), México:, Siglo XXI Editores, 2009. 169-173. . De los medios a las mediaciones. Comunicación, cultura y hegemonía. Barcelona: Ediciones G. Gili. S. A., 1987.

Masoliver Ródenas, Juan Antonio. “Juan Villoro: itinerarios de la invención”, Materias dispuestas: Juan Villoro ante la crítica, J. R. Ruisanchez y Oswaldo Zavala (Comp.). Barcelona, Candaya, 2011. 31-65. 
Monsiváis, Carlos. "Entre apariciones de la Venus de fuego (parte I). Irma Serrano”, él. La revista joven (octubre de 1973). 42-59, 108.

. "Entre apariciones de la Venus de fuego (parte II). Irma, "Tigresa", "Naná", Serrano", él. La revista joven (noviembre de 1973). 60-62, 102107. . "Literatura latinoamericana e industria cultural", Libros de México 15 (1989), p. 13-22.

Moreno, María. "Beatriz Guido: la pianista que no dio en la tecla”, Siete días 701 (1980). 46-50.

. “El estilo Claudia Sánchez”, Siete días 773 (1982). 36-41.

. "Sergio Víctor Palma: Ya me ven no soy Tarzán”, Siete días 778 (1982). 36-40.

. Vida de vivos. Conversaciones incidentales y retratos sin retocar. Buenos Aires: Sudamericana, 2005. . Subrayados. Leer hasta que la muerte nos separe. Buenos Aires: Mardulce, 2013.

Rama, Ángel. La ciudad letrada. Chile: Tajamar Editores, 2004.

Ricardez, Rosana: "Entrevista a Juan Villoro", La Clé des Langues [en ligne], Lyon, ENS de Lyon/Dgesco. http://cle.enslyon.fr/espagnol/litterature/entretiens-et-textesinedits/entretiens/entrevista-a-juan-villoro. abril de 2009

Rossi, Alejandro: "La casa gana", Materias dispuestas: Juan Villoro ante la crítica, J. R. Ruisanchez y Oswaldo Zavala (Comp.). Barcelona, Candaya, 2011. 82-86.

Salazar, Jezreel. La ciudad como texto: La crónica urbana de Carlos Monsiváis. Monterrey: Universidad Autónoma de Nuevo León, 2006.

Sánchez Prado, Ignacio. "Carlos Monsiváis: el intelectual público”. Naciones intelectuales: la modernidad literaria mexicana de la Constitución a la frontera (1917-2000). (Tesis doctoral). University of Pittsburgh, Pensilvania, 2006. 
Tentoni, Valeria. "Juan Villoro: 'no creo que haya literaturas individuales"” (2018). https://www.eternacadencia.com.ar/blog/contenidosoriginales/entrevistas/item/juan-villoro-no-creo-que-haya-literaturasindividuales.html

Villoro, Juan. Tiempo transcurrido (crónicas imaginarias). Distrito Federal: Fondo de Cultura Económica, 1999. . Safari accidental. México: Joaquín Mortiz, 2005. . Dios es redondo. Buenos Aires: Planeta, 2006. . 8,8: el miedo en el espejo. Una crónica del terremoto en Chile. Santiago de Chile: Universidad Diego Portales, 2010. - ¿Hay vida en la tierra? Buenos Aires: Marea, 2013. . Balón dividido. México: Planeta, 2015. . Palmeras de la brisa rápida. México: Almadía, 2017. . Los once de la tribu. México: Aguilar, 2017. . El vértigo horizontal. Barcelona: Anagrama, 2019.

Villoro, Juan y Martín Caparrós. Ida y vuelta. Una correspondencia sobre fútbol. Buenos Aires: Seix Barral, 2012.

Viú Adagio, Julieta. "La crónica después de la gran división. Carlos Monsiváis entre vedettes e ídolos", Literatura Mexicana, vol. 29, n. ${ }^{\circ} 1$. Enero-Junio de 2018. https://revistas-filologicas.unam.mx/literaturamexicana/index.php/lm/article/view/1063 125-144. 